\title{
Effect of Lattice Substitution on Adsorption of Hexavalent Chromium by Montmorillonite, Nontronite, and Beidellite
}

\author{
Weige Luo $\mathbb{B}$, Zheng Zeng *(1) and Liang Bian *(D) \\ School of Environment and Resource, Southwest University of Science and Technology, Mianyang 621010, China; \\ comeluoweige@163.com \\ * Correspondence: zengzheng@vip.163.com (Z.Z.); bianliang@swust.edu.cn (L.B.)
}

Citation: Luo, W.; Zeng, Z.; Bian, L. Effect of Lattice Substitution on Adsorption of Hexavalent Chromium by Montmorillonite, Nontronite, and Beidellite. Minerals 2021, 11, 1407. https://doi.org/10.3390/min11121407

Academic Editor: Felix Brandt

Received: 25 November 2021 Accepted: 10 December 2021 Published: 12 December 2021

Publisher's Note: MDPI stays neutral with regard to jurisdictional claims in published maps and institutional affiliations.

Copyright: (c) 2021 by the authors. Licensee MDPI, Basel, Switzerland. This article is an open access article distributed under the terms and conditions of the Creative Commons Attribution (CC BY) license (https:// creativecommons.org/licenses/by/ $4.0 /)$.

\begin{abstract}
This work aims to evaluate the effect of lattice substitution on adsorption of hexavalent chromium by three kinds of typical clay minerals, and its common isomorph via experiments and calculations were performed based on density functional theory. The experiments $\left(25^{\circ} \mathrm{C}, 4 \mathrm{~h}\right.$, $\mathrm{pH}=4$ and without stirring) confirmed an order of adsorption capacity as follows: Montmorillonite $(12 \mathrm{mg} / \mathrm{g})>$ Nontronite $(9 \mathrm{mg} / \mathrm{g})>$ Beidellite $(8 \mathrm{mg} / \mathrm{g})$. Accordingly, the Mulliken populations, density of states, and band structures of the mineral models with the structural $\mathrm{Al}, \mathrm{Mg}, \mathrm{Fe}(\mathrm{II}), \mathrm{Fe}(\mathrm{III})$, and $\mathrm{Al}$ (in tetrahedrons) on behalf of five species of isomorph were calculated. The calculation results explain the differences between hexavalent chromium adsorption capacity of five kinds of isomorph by means of atom, key populations, overlapping valence electron orbitals, and the variation of energy band. However, no overlapping orbitals were observed in the adsorption system with structural $\mathrm{Mg}$. It is implied that the structural $\mathrm{Mg}$ has little influence of hexavalent chromium adsorption. In conclusion, our study contributes to achieving a better understanding of modified clay minerals materials applications.
\end{abstract}

Keywords: hexavalent chromium; clay minerals; density functional theory; lattice substitution

\section{Introduction}

The industrial development has brought heavy metals such as chromium into a wide range of natural environments [1-3]. Chromium is usually found in soils and rocks in trivalent form; however, environmental conditions such as $\mathrm{pH}$ could convert it into a hexavalent form $[4,5]$. Hexavalent chromium can easily enter the food chain and threaten the human health, since its cellular toxicity can cause cancer and genetic variation [6]. Hence, adsorption and curing of chromium is a means for reducing its mobility.

Clay minerals are vital components of soil system, and the adsorption of cations on their surface plays an important role in migration and transformation of pollutants in soil. Montmorillonite, which is a natural adsorbent, and montmorillonite-based modified materials are widely used and studied to remove heavy metals from aqueous solutions [7-12]. It is well known that the specific surface and surface radicals make the adsorption of montmorillonite more complicated. Rathnayake et al. (2017) reported that the maximum adsorption capacity of $\mathrm{Cr}(\mathrm{VI})$ onto octadecyltrimethylammonium bromide-modified montmorillonite is $9.61 \mathrm{mg} / \mathrm{g}$ at $\mathrm{pH}=5.0$ [13]. Hu et al. (2010) modified montmorillonite with hydroxyaluminium and cetyltrimethylammonium to obtain a maximum adsorption capacity of $7.64-9.09 \mathrm{mg} / \mathrm{g}$ at $\mathrm{pH}$ $=4.0$ [14]. Johnatan et al. (2020) reported that the maximum adsorption capacity of $\mathrm{Cr}(\mathrm{VI})$ onto the hexadecyltrimethylammonium bromide-modified bentonite is $10.04 \mathrm{mg} / \mathrm{g}$ at $25^{\circ} \mathrm{C}$ and $\mathrm{pH}=3.4$ [15]. Such studies have confirmed that surface complexation provides more adsorption sites and can enhance the adsorption capacity.

Moreover, the negative surface charge which is resulted from lattice substitution also determines the adsorption capacity of clay minerals. Montmorillonite consists of $\mathrm{Si}-\mathrm{O}$ tetrahedrons and Al-O octahedrons, and exogenous metal cations $(2+/ 3+)$ could replace the $\mathrm{Al}$ in the octahedrons to cause the mineral to obtain a negative net charge. 
Hu et al. (2010) found that the surface charge and edge sites determine the adsorption of $\mathrm{Cr}(\mathrm{VI})$ by montmorillonite [14]. Abollino et al. (2003) assumed that the original surface radicals (Si-O-OH and $\mathrm{Al}-\mathrm{O}-\mathrm{OH}$ ) of montmorillonite have difficult adsorbing complexes with bivalent and trivalent cations [16], therefore the edge sites of montmorillonite seem to be the main adsorption sites. The edge sites mean the bare octahedral central metal cations and nontronite have a $\mathrm{Fe}(\mathrm{II} / \mathrm{III})-\mathrm{O}$ octahedron, and beidellite has an $\mathrm{Al}-\mathrm{O}$ tetrahedron compared to the pure montmorillonite. Namely, they are isomorphs, and the difference of their electronic constructure is resulted from the atom substitutions. Rajesh et al. (2017) found that the structural $\mathrm{Fe}$ (II) of nontronite combined with chitosan can form complexities and reduce the $\mathrm{Cr}(\mathrm{VI})$ in aqueous solutions [17]. Meanwhile, $\mathrm{Fe}(\mathrm{II})$ can directly reduce the $\mathrm{Cr}(\mathrm{VI})$. Based on the previous investigations, the knowledge of cations substitution was obtained as follows: (1) the $\mathrm{Fe}(\mathrm{II})$ adsorbs $\mathrm{Cr}$ (VI) by its reducibility; (2) whether the $\mathrm{Fe}(\mathrm{III})$ has a direct interaction with $\mathrm{Cr}(\mathrm{VI})$ is unclear, but external reducing agents like organic acids cause $\mathrm{Fe}(\mathrm{III})$ to complement $\mathrm{Fe}$ (II) to activate adsorption [18]; (3) beidellite has a stronger adsorption capacity for some heavy metals $(71.07 \mathrm{mg} / \mathrm{g}$ [19] $>25.50 \mathrm{mg} / \mathrm{g}$ [20], $\mathrm{Cu}(\mathrm{II})$ ); and (4) montmorillonite from different regions has different adsorption capacity $(24.5 \mathrm{mg} / \mathrm{g}$ [21] $>7.64-10.04 \mathrm{mg} / \mathrm{g}$ [13-15]). The difference between the maximum adsorption capacity of montmorillonite from different regions is probably caused by $\mathrm{Mg}$, which is a common dopant component in natural montmorillonite. Even today, the effect of lattice substitution on $\mathrm{Cr}(\mathrm{VI})$ adsorption remains uncertain.

To investigate the effect of lattice substitution on $\mathrm{Cr}(\mathrm{VI})$ adsorption, density functional theory (DFT) was used. The density functional theory is a state-of-the-art approach, and allows people to solve the Schrödinger equation for a multi-electron system by using Born-Oppenheimer approximation [22] and the Hartree-Fock approximation [23]. Based on the coulomb interactions between electrons, it treats all particles in a multielectron system as identical particles, and the electron density was used as the variable of the energy functional theory for the calculation of the ground-state energy of the system so as to describe the physical properties of the ground state of atoms, molecules, and solids, and the relationships between the electronic structure and energy of the system. Hence, the famous Hohenberg-Kohn theorem described the energy state of inhomogeneous electronic gas in detail, and laid the theoretical foundation of density functional [24]. To further determine the commutative correlation energy functional, Kohn and Sham proposed the Kohn-Sham equation [25] to solve the electron density and energy of the system through the self-consistent field cycle [26]. The local density approximation (LDA) and generalized gradient approximation (GGA) were presented to fill in blank of the potential energy between electrons in Kohn-Sham equation [27,28]. LDA is more suitable for the computation of metal systems [29], and GGA is more widely applicable [30,31], especially for the calculation of mineral surface and interface. Namely, GGA is more suitable for this research. Thus far, density functional theory has been generally complete but is still in continuous development.

Meanwhile, some methods and software have been developed to calculate the specific reaction system based on density functional theory. Examples emerge from the simulated annealing method based on grand canonical Monte Carlo principle, which is used to calculate the optimum adsorption sites by comparing the configuration energy of adsorption system [32]; Castep and Dmol3 module of Material studio software used to calculate the energy of periodic and aperiodic systems, respectively [33,34]. Hence, a mineral reaction system is more suitable for calculation with the Castep module. Mulliken population of Castep is used to indicate the bonding nature and electron transfer of systems; however, results of Mulliken population are incomplete due to the non-localization of ground-state atoms. Therefore, electron localization function is used in conjunction with Mulliken population. Besides, the density of state and band structure of minerals not only indicates the properties of electron energy, but also includes optical properties [35] and electrical conductivity [36]. Consequently, it is highly convenient and effective to use density functional theory to solve such basic theoretical problems. 
This paper aims to evaluate the effect of different lattice substitution $\left(\mathrm{Mg}^{2+}, \mathrm{Fe}^{2+}\right.$, $\mathrm{Fe}^{3+}$, and $\mathrm{Al}^{3+}$ ) of montmorillonite on $\mathrm{Cr}(\mathrm{VI})$ adsorption. The experimental results and adsorption mechanism are explained by the variation of electron transfer and frontier orbital calculated by density functional theory. Given the effect of cation substitution on heavy metal adsorption is rarely investigated directly, and differences in adsorption and electronic properties caused by isomorphism being distinct [37], this study on the adsorption mechanism of $\mathrm{Cr}(\mathrm{VI})$ by montmorillonite and its isomorph has certain significance for modified clay minerals applications.

\section{Materials, Methods and Models}

\subsection{Minerals}

The montmorillonite, nontronite, and beidellite were purchased from Aladdin company, Shanghai China. The X-ray diffraction (XRD, CuK $\alpha$-ray, X Pert pro, PANalytical B.V, Almelo, Netherlands) curves proved the purity at $25^{\circ} \mathrm{C}$ and the $\mathrm{X}$-ray fluorescence (XRF, Axios $2.4 \mathrm{~kW}$, PANalytical B.V, Almelo, Netherlands) results showed the chemical composition of three clay minerals (Figure 1 and Table 1 ).

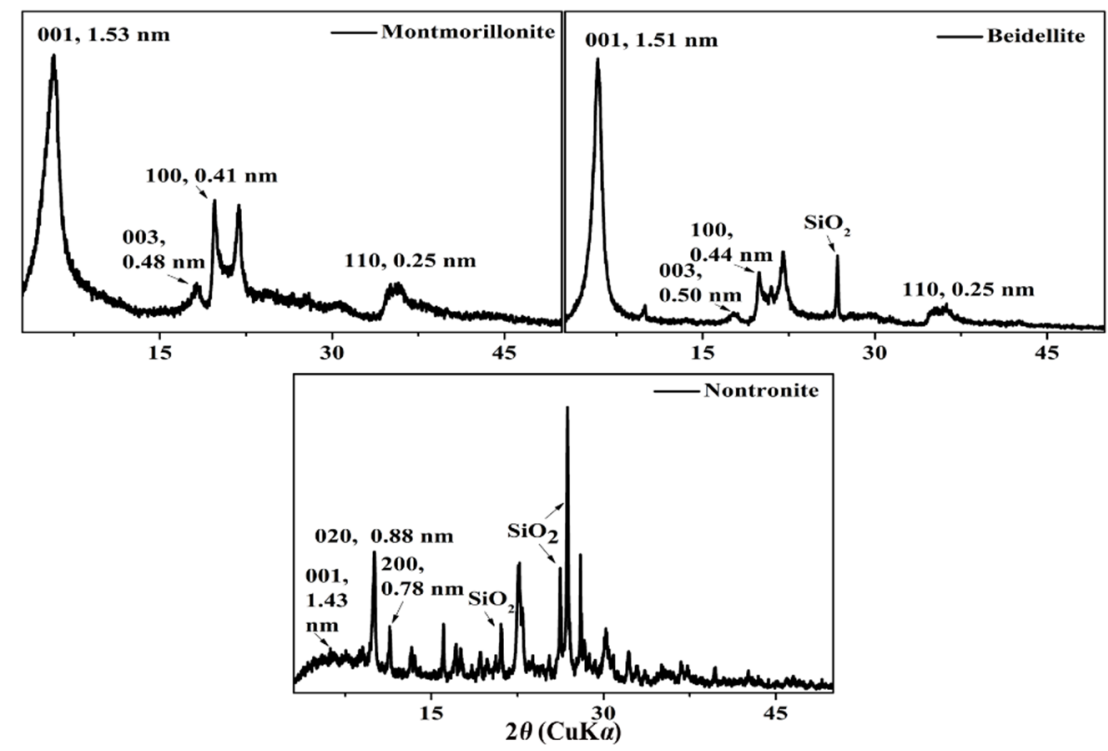

Figure 1. The XRD curves of three clay minerals.

Table 1. The XRF results of three clay minerals. (Unit: $w t \%)$. \: undetected

\begin{tabular}{cccc}
\hline Components & Montmorillonite & Nontronite & Beidellite \\
\hline $\mathrm{SiO}_{2}$ & 50.19 & 59.54 & 59.22 \\
$\mathrm{Al}_{2} \mathrm{O}_{3}$ & 22.42 & 11.18 & 11.78 \\
$\mathrm{Fe}_{2} \mathrm{O}_{3}$ & 3.16 & 1.68 & 0.89 \\
$\mathrm{MgO}_{2}$ & 1.94 & 1.06 & 3.76 \\
$\mathrm{Cl}$ & 0.74 & $\backslash$ & $<0.01$ \\
$\mathrm{SO}_{3}$ & 0.59 & $\backslash$ & 0.02 \\
$\mathrm{TiO}_{2}$ & 0.36 & 0.26 & $\backslash$ \\
$\mathrm{CaO}$ & 0.18 & 2.75 & 3.06 \\
$\mathrm{~K}_{2} \mathrm{O}$ & 0.14 & 2.11 & 0.43 \\
$\mathrm{Na}_{2} \mathrm{O}$ & 0.12 & 1.06 & 0.53 \\
\hline
\end{tabular}




\subsection{Adsorption Experiments}

The $\mathrm{Cr}(\mathrm{VI})$ stock solution $(30 \mathrm{mg} / \mathrm{L})$ was prepared by dissolving sodium chromate $\left(\mathrm{Na}_{2} \mathrm{CrO}_{4}\right)$ in $50 \mathrm{~mL}$ deionized water. In view of the strong oxidizing property of $\mathrm{CrO}_{4}{ }^{2-}$, the dilute sulfuric acid was used to control the solution $\mathrm{pH}=4$ [14]. $0.5 \mathrm{~g}$ montmorillonite, nontronite, and beidellite were added to the $50 \mathrm{~mL} \mathrm{Cr}(\mathrm{VI})$ solution, respectively. The reaction lasted for $4 \mathrm{~h} \mathrm{[38]} \mathrm{at} \mathrm{the} \mathrm{room} \mathrm{temperature} \mathrm{without} \mathrm{stirring.} \mathrm{The} \mathrm{supernatant} \mathrm{was}$ filtered with a 0.45 -micron aqueous microporous membrane and stored at $4{ }^{\circ} \mathrm{C}$, and tested within $24 \mathrm{~h}$. The residual minerals were washed slightly with deionized water 10 times and dried at $60^{\circ} \mathrm{C}$, stored at $4{ }^{\circ} \mathrm{C}$, and tested within $24 \mathrm{~h}$.

\subsection{Analyses}

The residual $\mathrm{Cr}(\mathrm{VI})$ of upper liquid was measured by inductively coupled plasma optical emission spectroscopy (ICP-OES, Thermo iCAP6500, Thermo Fisher, Waltham, MA, USA). The scanning electron microscopy-energy dispersive spectroscopy (SEM-EDS, TM4000, Hitachi, Tokyo, Japan) was used to confirm that adsorption had occurred.

\subsection{Computational Methods}

The structure mode of Ca-montmorillonite [39] and nontronite [40] were obtained through the geometric optimization, whereas the structure mode of beidellite was obtained through atom substitution. The crystal parameter after geometric optimization (montmorillonite: $\mathrm{a}=1.04 \mathrm{~nm}, \mathrm{~b}=0.89 \mathrm{~nm}, \mathrm{c}=1.50 \mathrm{~nm}, \alpha=\beta=\gamma=90^{\circ}$; nontronite: $\mathrm{a}=0.53 \mathrm{~nm}, \mathrm{~b}=0.91 \mathrm{~nm}, \mathrm{c}=1.00 \mathrm{~nm}, \alpha=\gamma=90^{\circ}, \beta=104^{\circ}$; beidellite: $\mathrm{a}=1.01 \mathrm{~nm}$, $\mathrm{b}=1.00 \mathrm{~nm}, \mathrm{c}=1.51 \mathrm{~nm}, \alpha=\gamma=90^{\circ}, \beta=89^{\circ}$ ) were consistent with the reported values (montmorillonite: $\mathrm{a}=1.04 \mathrm{~nm}, \mathrm{~b}=0.90 \mathrm{~nm}, \mathrm{c}=1.50 \mathrm{~nm}, \alpha=\beta=\gamma=90^{\circ}$; nontronite: $\mathrm{a}=0.53 \mathrm{~nm}, \mathrm{~b}=0.91 \mathrm{~nm}, \mathrm{c}=0.98 \mathrm{~nm}, \alpha=\gamma=90^{\circ}, \beta=101^{\circ}$; beidellite: $\mathrm{a}=1.04 \mathrm{~nm}, \mathrm{~b}=0.90$ $\left.\mathrm{nm}, \mathrm{c}=1.50 \mathrm{~nm}, \alpha=\beta=\gamma=90^{\circ}\right)[39,40]$. To investigate the edge sites adsorption process, a 2 -nm vacuum region in the $\mathrm{x}$ direction was employed. Afterwards, a $2 \times 1 \times 1$ super cell was built, which has 76 atoms (Figure 2). Moreover, under acidic conditions, there is a conversion reaction of $\mathrm{CrO}_{4}{ }^{2-}$ and $\mathrm{Cr}_{2} \mathrm{O}_{7}{ }^{2-}$. As a result, the molecular model of $\mathrm{Cr}_{2} \mathrm{O}_{7}{ }^{2-}$ $(0.655 \mathrm{~nm})$ was built to simulate the adsorption.

The conversion reaction at $\mathrm{pH}=4$ :

$$
2 \mathrm{CrO}_{4}^{2-}+2 \mathrm{H}^{+} \rightarrow \mathrm{Cr}_{2} \mathrm{O}_{7}^{2-}+\mathrm{H}_{2} \mathrm{O}
$$

All grand canonical Monte Carlo and quantum mechanical calculations were based on adsorption locator and Castep modules from Materials Studio 7.0, respectively. The adsorption locator found the optimum adsorption sites with the lowest energy configuration through the simulated annealing method [32,41]. The structure optimization and properties calculation of all models were performed by quantum mechanical calculations based on DFT using the GGA (generalized gradient approximation) and PBE (PerdewBurke-Ernzerhof) exchange correlation functional [42-45]. The short-range van-der-Waals and long-range electrostatic interactions were simulated by the atom-based and Ewald methods, respectively. Therein, the Tkatchenko-Scheffler method for DFT + D correction was used to the correct dispersive interaction [46]. The highly accurate full potential projector augmented wave (PAW) method with ultra-soft pseudopotentials was used to describe the electron-ion interactions in the valence band region. Brillouin-zone integrations were calculated with a $\gamma$-centered $3 \times 3 \times 3$ Monkhorst-Pack k-point mesh. The convergence criteria for the energy, maximum force, maximum displacement, and SCF tolerance were set to $1.0 \times 10^{-5} \mathrm{eV} /$ atom, $1.0 \times 10^{-2} \mathrm{eV} / \mathrm{A}, 1.0 \times 10^{-3} \mathrm{~nm}, 1.0 \times 10^{-4} \mathrm{eV} /$ atom, respectively. 

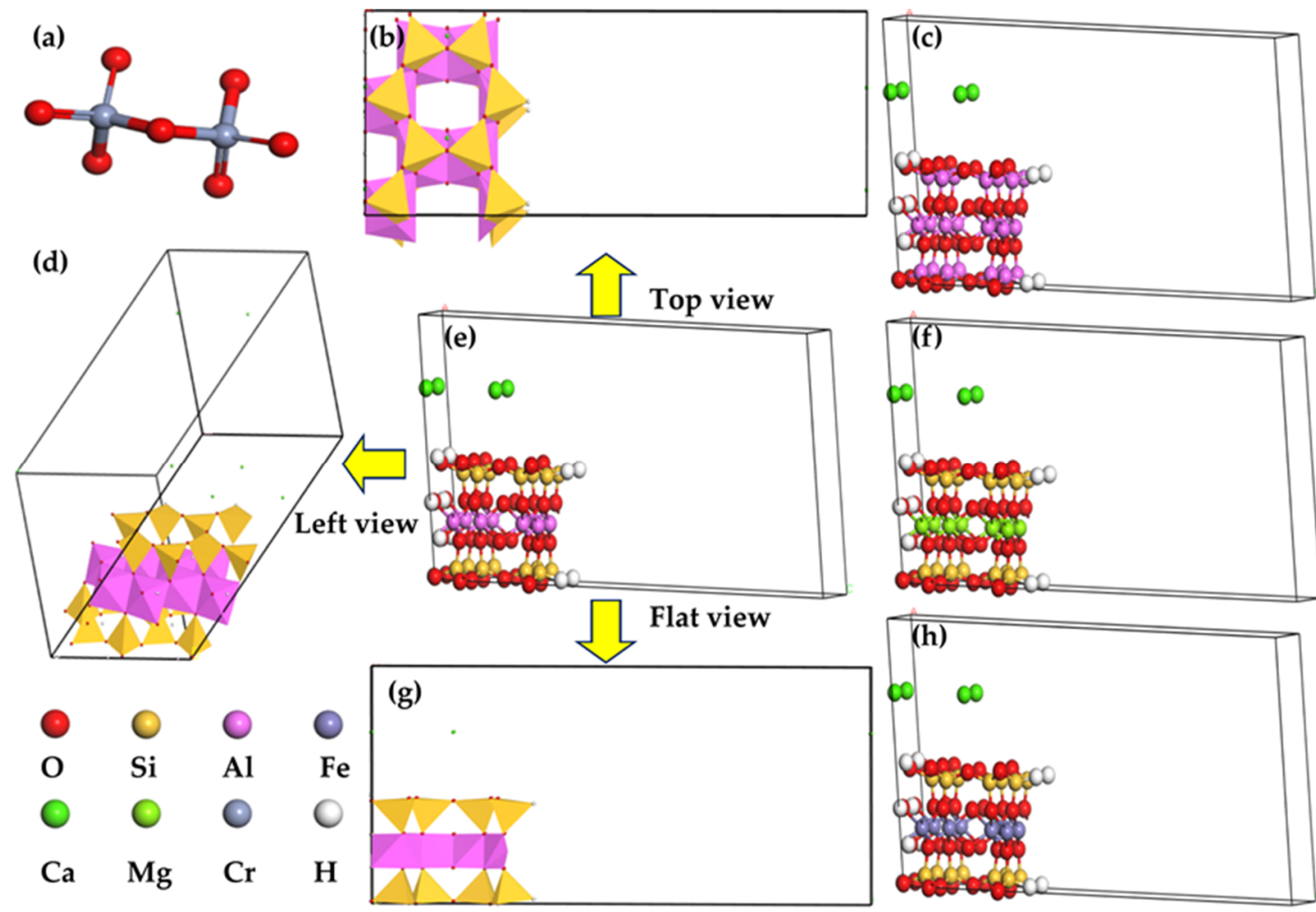

Figure 2. The established structure model of (a) $\mathrm{Cr}_{2} \mathrm{O}_{7}{ }^{2-}$, (b) Top view of montmorillonite, (c) beidellite, (d) left view of montmorillonite, (e) montmorillonite, (f) montmorillonite- $\mathrm{Mg}$, (g) flat view of montmorillonite and (h) nontronite.

\section{Results and Discussion}

\subsection{The Remaining $\mathrm{Cr}(V I)$ Content in the Solution}

The residual $\mathrm{Cr}(\mathrm{VI})$ content is displayed in Table 2 . The adsorption capacity of montmorillonite, nontronite, and beidellite were 12,9 , and $8 \mathrm{mg} / \mathrm{g}$, respectively. As shown in Figure 2, the lattice of these three minerals consists of $\mathrm{X}-\mathrm{O}$ octahedron and two $\mathrm{Y}-\mathrm{O}$ tetrahedrons; the cation-doped X, Y-site is the main difference between these three minerals. Therefore, it may be concluded that the cations substitution weakens the adsorption of $\mathrm{Cr}(\mathrm{VI})$.

Table 2. Residual chromium content in the solution.

\begin{tabular}{ccc}
\hline Minerals & Residual Concentration $(\mathbf{m g} / \mathbf{L})$ & Initial Concentration $(\mathbf{m g} / \mathbf{L})$ \\
\hline Montmorillonite & 18 & 30 \\
Nontronite & 21 & 30 \\
Beidellite & 22 & 30 \\
\hline
\end{tabular}

\subsection{The Adsorption of $\mathrm{Cr}(\mathrm{VI})$ on Mineral Surfaces}

The adsorption of $\mathrm{Cr}(\mathrm{VI})$ by three clay minerals was investigated through SEM and EDS. At $\times 5000$ times magnification, the SEM images displayed the surface morphology directly, and the mapped images showed that $\mathrm{O}, \mathrm{Si}$, and $\mathrm{Al}$ from the basic mineral skeleton and the $\mathrm{Cr}(\mathrm{VI})$ are distributed on the surface, which indicates adsorption occurred (Figure 3). Therein, a bumpy surface of nontronite gathers $\mathrm{Cr}(\mathrm{VI})$ more densely compared to the relatively smooth surface of montmorillonite. The uneven surface provides more adsorption sites by means of increasing specific surface area or increasing number of bared atoms [47], which contributes to a denser gathering of chromium or directly enhances the maximum adsorption capacity. However, a surface structural defect of beidellite has sparse distribution of $\mathrm{Cr}(\mathrm{VI})$. Since montmorillonite with a flat surface also adsorbs more $\mathrm{Cr}(\mathrm{VI})$ than nontronite and beidellite with uneven surface, we believe the SEM-EDS results of the effect of cation substitution on $\mathrm{Cr}(\mathrm{VI})$ adsorption rather than surface morphology 
would be prominent. It is implied that $\mathrm{Al}^{3+}$ replacement by $\mathrm{Si}^{4+}$ in tetrahedron reduced the adsorption of $\mathrm{Cr}(\mathrm{VI})$ by exposed atoms. The recent research shows that the adsorption of edge surfaces of montmorillonite is more efficient for heavy metals than beidellite [48]. However, the adsorption of bedonite to organic matter such as metachromatic dye acridine orange is greater than that of montmorillonite [49], and there is little difference of adsorption of uranyl between beidellite and montmorillonite [50]. The selective adsorption may have resulted from the electronic structure of the adsorbate. In addition, the approximate values of mass fraction as a supplement are identical to the ICP-OES results that suggest montmorillonite has the highest $\mathrm{Cr}(\mathrm{VI})$ mass fraction of $3.422 \mathrm{wt} \%$, while nontronite and beidellite have a declining $\mathrm{Cr}(\mathrm{VI})$ mass fractions of 1.918 and $1.627 \mathrm{wt} \%$, respectively (Figure 4).
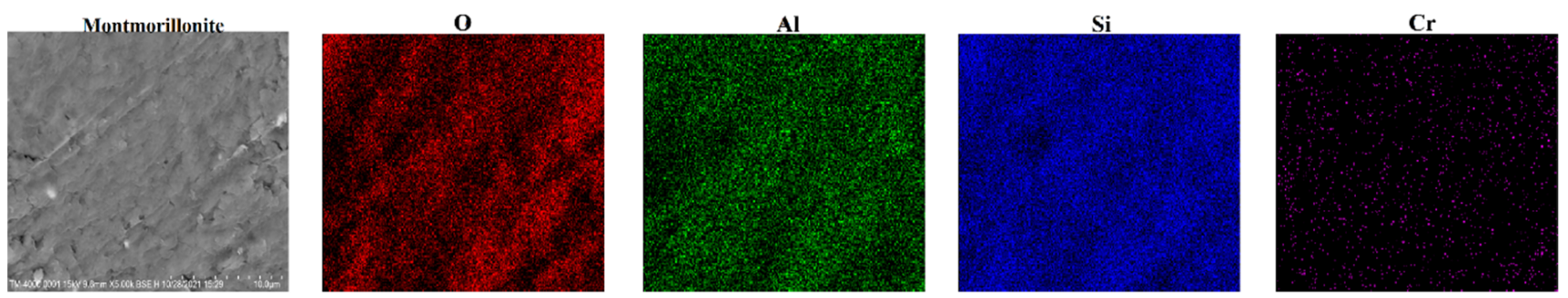

Nontronite
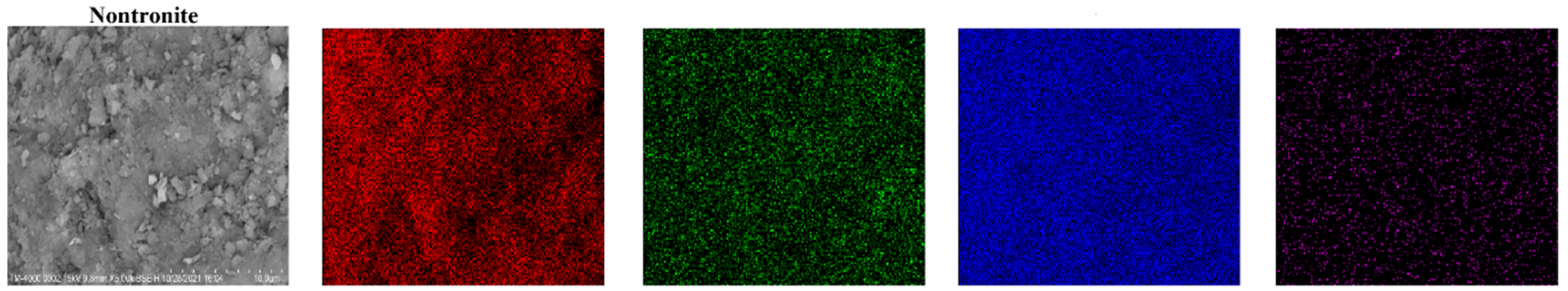

Beidellite
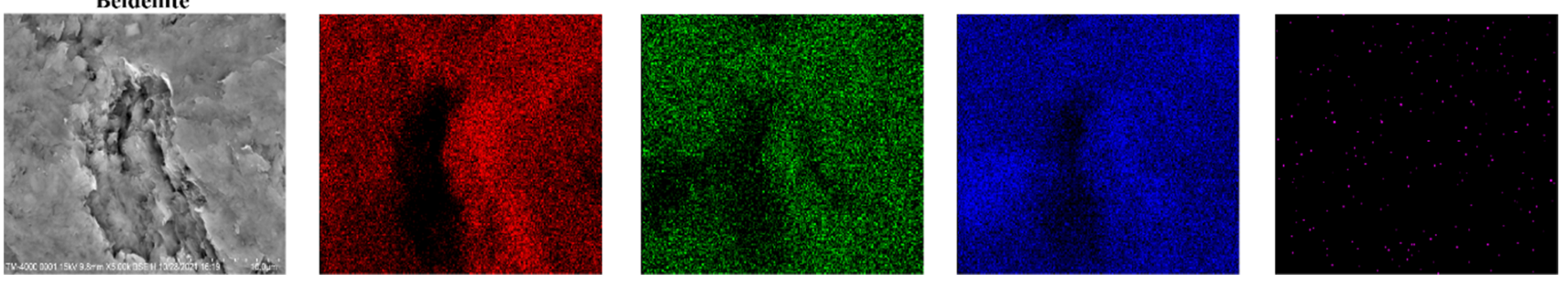

Figure 3. SEM images of three clay minerals surface. The mapped images of $\mathrm{O}, \mathrm{Al}$, Si examined the skeleton of clay minerals, and the mapped images of $\mathrm{Cr}$ showed a surface adsorption may occurred. Thought the comparison of morphology and $\mathrm{Cr}$ surface distribution, $\mathrm{Cr}$ adsorption is not determined by surface morphology. 


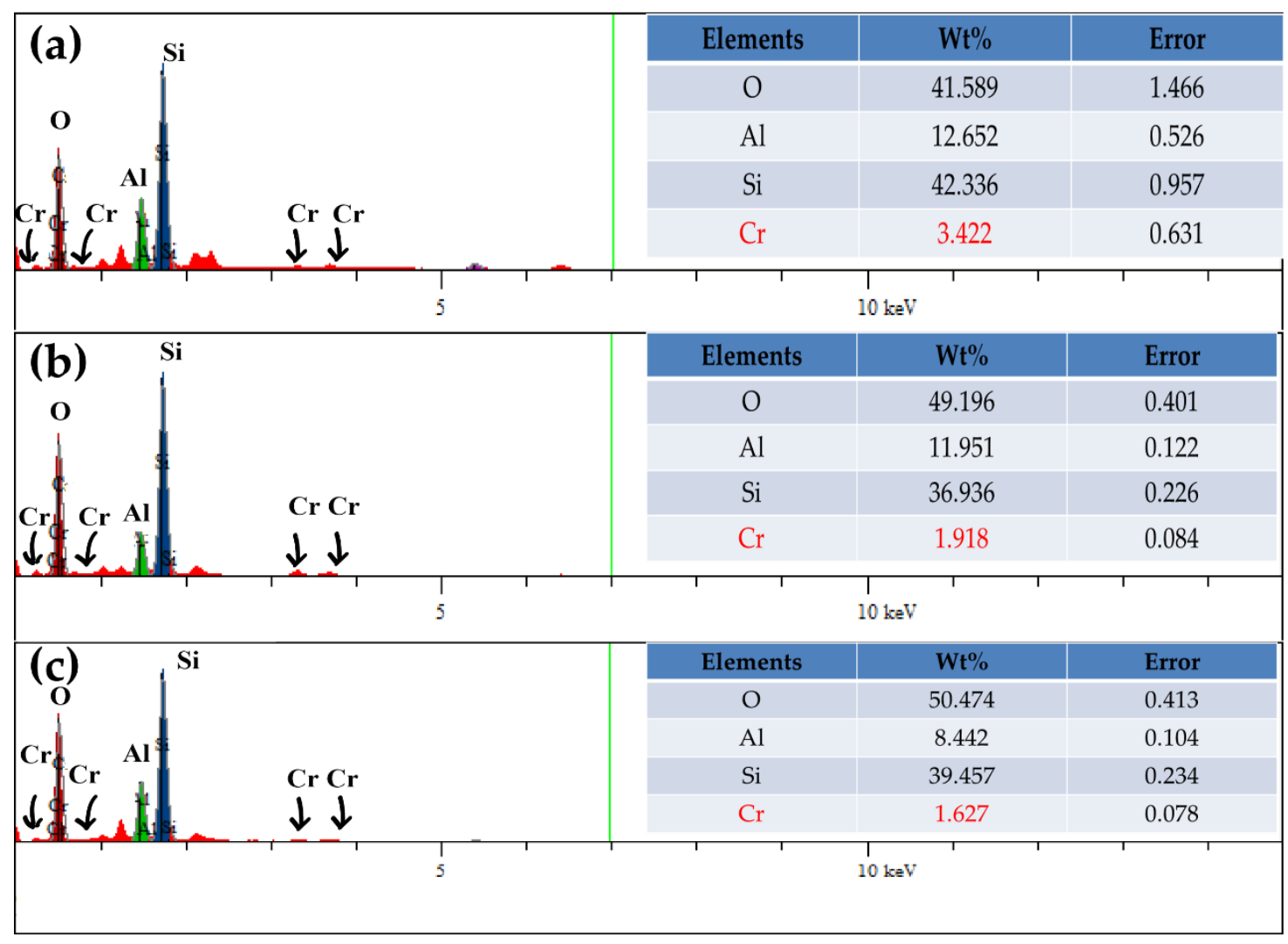

Figure 4. EDS results of elements on the surface of three clay minerals. The $(\mathbf{a}-\mathbf{c})$ images represent results of montmorillonite, nontronite, and beidellite, respectively. The approximate mass fraction of $\mathrm{Cr}$ supplements the ICP-OES results.

\subsection{Mulliken Populations of Crystal Structure and Adsorption Bond}

The Mulliken populations directly display the distribution of electrons among atoms in crystal structure and describe the stability of chemical bonds. The Mulliken atom populations are compared with reported data $[41,51-53]$ in Table 3 . The obtained atom populations are similar to the reported values, with the exception of Mg. Therein, the deviation of charges is due to the different initial montmorillonite model and species of interlayer cations. In general, the crystal structure of montmorillonite and beidellite, and nontronite-(II) and nontronite-(III) are similar to each other, respectively. The $\mathrm{Al}_{\mathrm{T}}(\mathrm{Al}$ in the tetrahedron) donates fewer electrons than $\mathrm{Al}_{\mathrm{O}}$ ( $\mathrm{Al}$ in the octahedron). Meanwhile, in the presence of $\mathrm{Al}_{\mathrm{T}}$, the $\mathrm{Al}_{\mathrm{O}}$ also has a reduced electron donation by approximately $0.14 \mathrm{e}$. The structural Fe(II/III) of nontronite has almost no influence on atom populations. Moreover, the Fe donates the fewest electrons compared to the other three kinds of lattice substitution. The $\mathrm{Mg}$ substitution in octahedrons results in the redistribution of electrons between $\mathrm{Si}$ and $\mathrm{O}$ atoms. In other words, electrons are transferred from $\mathrm{Si}$ to $\mathrm{O}$ atoms. Comparing Tables 3 and 4, for montmorillonite adsorption system, the $\mathrm{Cr}(\mathrm{VI})$ adsorption leads to a slight loss in $\mathrm{O}$ and Si charge by approximately $0.01 \mathrm{e}$, whereas $\mathrm{Al}$ shows a 0.09 e increase in charge. The $\mathrm{Al}_{\mathrm{O}}$ and $\mathrm{Al}_{\mathrm{T}}$ of the beidellite adsorption system gain $0.06 \mathrm{e}$ and $0.01 \sim 0.02 \mathrm{e}$, respectively. A slight atom population increase is also observed in the montmorillonite- $\mathrm{Mg}$ adsorption system (i.e., 0.04 e). However, the $\mathrm{Fe}(\mathrm{II})$ and $\mathrm{Fe}(\mathrm{III})$ give a 0.03 e charge to the lattice. Since the electronegativity of $\mathrm{Fe}^{3+}$ is 0.22 higher than $\mathrm{Al}^{3+}(1.83>1.61)$ and the charge population of $\mathrm{Fe}^{3+}$ is 0.89 e lower than $\mathrm{Al}^{3+}$ (Table 3), the structural Fe seems to possess more charge to donate to other atoms while adsorption occurs. In addition, the $\mathrm{O}$ in $\mathrm{Cr}_{2} \mathrm{O}_{7}{ }^{2-}$, which has formed adsorption bonds with bare central octahedral atoms, has an increased charge population by approximately $0.3 \sim 0.4 \mathrm{e}$ in all adsorption systems, and the nearby $\mathrm{Cr}^{6+}$ has experienced an increase of $0.01 \sim 0.06 \mathrm{e}$. It is implied that more charge is induced in $\mathrm{O}$ atom which used to form the adsorption bond. 
The bond populations intuitively describe the stability of bonds and its bond type, namely ionic or covalent bond [54,55] (Table 5). The higher the bond populations, the more intensive the density of the overlapping electron clouds in orbitals, and the more stable the bonds. The charge of $\mathrm{Al}-\mathrm{O}$ bonds of montmorillonite has increased by $0.09 \mathrm{e}$ and the charge of the $\mathrm{Si}-\mathrm{O}$ bonds remains the same. As a result, the octahedrons become unstable, while the tetrahedrons remain unaffected. Similar to the case of the nontronite-(II) adsorption system, the octahedrons become unstable with a 0.11 e charge obtained, and tetrahedrons remain the same. The variations of nontronite-(III) bond populations are the opposite. The charge of $\mathrm{Fe}-\mathrm{O}$ bonds only changed by $0.01 \mathrm{e}$ and the $\mathrm{Si}-\mathrm{O}$ bonds obtained 0.22 e charge, which resulted in the reinforcement for tetrahedrons stability. The bond populations $(0.08 \sim 0.44 \mathrm{e})$ for beidellite implied that the structure of beidellite is less stable than the other four isomorphs. The adsorption enhanced the Al-O bonds, which obtained a charge equal to $0.17 \sim 0.32$ e. Peng et al. (2019) calculated the adsorption bond of surface hydroxy with $\mathrm{Y}^{3+}$ is $0.24 \sim 0.41 \mathrm{e}$, and it is a covalent bond [56]. The values of obtained adsorption bond populations of all systems except montmorillonite-Mg are $0.12 \sim 0.52 \mathrm{e}$, which are covalent bonds. It is worth mentioning that the antibonding orbitals were found in the octahedrons of montmorillonite- $\mathrm{Mg}$ and the corresponding adsorption system. Meanwhile, the value of $\mathrm{Mg}-\mathrm{O}$ adsorption bond is $-0.47 \mathrm{e}$, which appears to be a covalent bond. In view of molecular orbital theory, bonding orbitals and antibonding orbitals always appear in pairs, and antibonding orbitals require higher energy electrons to occupy them. Hence, a covalent bond seems hardly formed in an antibonding orbital since the high energy barrier of antibonding orbital seems to be in contradiction to electron sharing. Considering the bond population of octahedrons of montmorillonite- $\mathrm{Mg}$, there are covalent and ionic bonds. Zhang et al. (2021) considered the antibonding orbital valued $-0.02 \sim-0.09$ e as the covalent bonds [57]. However, the obtained antibonding orbital valued $-0.24 \sim-1.67$ e are at least 20 times higher than Zhang's results, thus the bonds connecting Mg and octahedron perhaps are ionic bonds. Hence, discovering whether the octahedrons constructed by antibonding orbitals are stable requires further calculation of electrons energy. It is clear that by considering only the variations of bond populations, the antibonding orbitals in octahedrons and bonding orbitals in tetrahedrons both become more stable. Comparing all adsorption bond populations, the nontronite-Fe(II/III) adsorption systems have the most stable chemical bonds ( $0.50 \sim 0.52 \mathrm{e})$, and beidellite has $0.12 \mathrm{e}$ bond strength, indicating that beidellite has the weakest chromium adsorption capacity. This is consistent with the ICP-OES and SEM-EDS results.

Table 3. Atom populations(e) of original minerals. $\backslash$ : null value

\begin{tabular}{|c|c|c|c|c|c|c|}
\hline Minerals & $\mathbf{O}$ & $\mathbf{A l}_{\mathrm{O}}$ & $\mathrm{Si}$ & $\mathrm{Fe}$ & Mg & $\mathbf{A l}_{\mathrm{T}}$ \\
\hline Montmorillonite & $\begin{array}{c}-1.16 \sim-1.20 /-1.12[41] / \\
-1.00 \sim-1.06[51] / \\
-1.05[52,53]\end{array}$ & $\begin{array}{l}1.98 / 2.01[41] / \\
1.58[53]\end{array}$ & $1.88 \sim 2.27 / 2.10$ [53] & 1 & 1 & 1 \\
\hline Nontronite-Fe(II) & $-0.90 \sim-0.96 /-1.16[41]$ & 1 & $1.83 \sim 2.22$ & $\begin{array}{c}1.08 / 1.03[41] / \\
1.58[53]\end{array}$ & 1 & 1 \\
\hline Nontronite-Fe(III) & $-0.90 \sim-0.96 /-1.16[41]$ & 1 & $1.86 \sim 2.22$ & $\begin{array}{c}1.09 / 1.03[41] / \\
1.58[53]\end{array}$ & 1 & 1 \\
\hline Montmorillonite-Mg & $-1.26 \sim-1.29 /-1.12[41]$ & 1 & $1.79 \sim 2.18$ & 1 & $\begin{array}{c}1.69 / 2.40[41] / \\
1.36[53]\end{array}$ & 1 \\
\hline Beidellite & $-1.18 \sim-1.20$ & $1.84 / 2.01[41]$ & 1 & 1 & 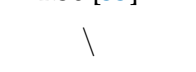 & $\begin{array}{c}1.66 \sim 1.88 / \\
1.58[53]\end{array}$ \\
\hline
\end{tabular}

Notes: The $\mathrm{Al}_{\mathrm{O}}$ and $\mathrm{Al}_{\mathrm{T}}$ represent $\mathrm{Al}$ in the octahedrons and tetrahedrons, respectively. 
Table 4. Atom populations (e) of adsorption system. $\backslash:$ null value

\begin{tabular}{|c|c|c|c|c|c|c|c|c|}
\hline Substance & $\mathrm{O}($ mineral $)$ & Al(mineral) & Si(mineral) & Mg & $\mathbf{F e}$ & $\mathrm{O}\left(\mathrm{Cr}_{2} \mathrm{O}_{7}^{2-}\right)$ & $\mathrm{Cr}_{-1}$ & $\mathrm{Cr}_{-2}$ \\
\hline $\mathrm{Cr}_{2} \mathrm{O}_{7}^{2}$ & 1 & & 1 & & $\backslash$ & $-0.32 \sim-0.34$ & 1.29 & 1.29 \\
\hline Montmorillonite & $-1.15 \sim-1.18$ & 1.87 & $1.85 \sim 2.26$ & & 1 & $-0.43 \sim-0.83$ & 1.33 & 1.27 \\
\hline Nontronite-Fe(II) & $-0.85 \sim-0.92$ & 1 & $1.79 \sim 2.21$ & & 1.12 & $-0.39 \sim-0.63$ & 1.30 & 1.24 \\
\hline Nontronite-Fe(III) & $-0.84 \sim-0.91$ & 1 & $1.81 \sim 2.24$ & & 1.14 & $-0.42 \sim-0.59$ & 1.30 & 1.25 \\
\hline Montmorillonite-Mg & $-1.14 \sim-1.27$ & & $1.75 \sim 2.13$ & 1.65 & $\backslash$ & $-0.32 \sim-0.71$ & 1.31 & 1.23 \\
\hline Beidellite & $-1.18 \sim-1.19$ & $1.79 / 1.65 \sim 1.86^{\mathrm{a}}$ & 1 & $\backslash$ & 1 & $-0.33 \sim-0.79$ & 1.35 & 1.28 \\
\hline
\end{tabular}

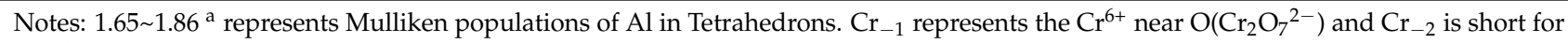
another.

Table 5. Comparison between bond populations(e).

\begin{tabular}{cccccc}
\hline \multirow{2}{*}{ Minerals } & \multicolumn{2}{c}{ Original Mineral } & \multicolumn{2}{c}{ Adsorption System } & $\mathbf{C r}_{2} \mathbf{O}_{7}{ }^{2-}$ \\
\cline { 2 - 6 } & $\mathbf{X}-\mathbf{O}$ & $\mathbf{Y}-\mathbf{O}$ & $\mathbf{X}-\mathbf{O}$ & $\mathbf{Y}-\mathbf{O}$ & $\mathbf{X}-\mathbf{O}$ \\
\hline Montmorillonite & $0.19 \sim 0.39$ & $0.47 \sim 0.63$ & $0.18 \sim 0.48$ & $0.49 \sim 0.62$ & 0.48 \\
Nontronite-Fe(II) & $0.17 \sim 0.41$ & $0.53 \sim 0.60$ & $0.17 \sim 0.52$ & $0.48 \sim 0.60$ & 0.52 \\
Nontronite-Fe(III) & $0.17 \sim 0.41$ & $0.50 \sim 0.82$ & $0.17 \sim 0.42$ & $0.48 \sim 0.60$ & 0.50 \\
Montmorillonite-Mg & $-0.24 \sim-1.52$ & $0.47 \sim 0.67$ & $-0.31 \sim-1.67$ & $0.39 \sim 0.78$ & -0.47 \\
Beidellite & $0.08 \sim 0.44$ & $0.08 \sim 0.44$ & $0.40 \sim 0.62$ & $0.38 \sim 0.61$ & 0.12 \\
\hline
\end{tabular}

Notes: $\mathrm{X}$ represents the octahedral central atoms $\left(\mathrm{Al}^{3+}, \mathrm{Fe}^{2+}, \mathrm{Fe}^{3+}\right.$ or $\left.\mathrm{Mg}^{2+}\right)$ and $\mathrm{Y}$ represents the tetrahedral central atoms $\left(\mathrm{Si}^{4+}\right.$ or $\left.\mathrm{Al}^{3+}\right)$.

\subsection{Electron Localization Function Interprets the Nature of Bonding}

In view of the ground-state atoms provided by the plane wave basis group are nonlocality, electron localization function (Elf) needs to be calculated as a supplement to describe the bonding nature of adsorption systems. The electron localization function normalizes the degree to which an electron is bound, so the desired Elf-value is between 0 1. Long pair electrons should be considered highly localized, and covalent bond electrons should be considered relatively delocalized [58]. Hence, the adsorption bonds of montmorillonite, nontronite-Fe(II/III), and beidellite are the covalent bonds due to an Elf-value lower than 0.5 (Figure 5a-e). The adsorption bond of montmorillonite- $\mathrm{Mg}$ seems to be an ionic bond (Figure $5 \mathrm{~d}$ ), owing to bond electrons close to $\mathrm{O}$ atom which are highly localized; however, the electrons close to $\mathrm{Mg}$ atom are highly delocalized [59]. From the aspect of the Pauling electronegativity (EN, scale is 0 3.98) [60] of atoms, the $\mathrm{Mg}$ (1.31) forms an ionic bond with $\mathrm{O}$ (3.44) easier than $\mathrm{Al}$ (1.61) and $\mathrm{Fe}$ (1.83). Moreover, the lattice structure of montmorillonite-Mg appears more highly localized electrons (the red areas in Figure 5d). The red area means that a large number of electrons are bound around by atoms, and it is in accordance with the bond population results that montmorillonite-Mg has many antibonding orbitals, which have high energy barrier to prevent electrons from entering into orbitals. Therefore, electrons are restricted in a small space, namely they embody a highly localization. It is worth noting that the $\mathrm{O}$ atoms of $\mathrm{Cr}_{2} \mathrm{O}_{7}{ }^{2-}$ in montmorillonite-Mg system also appear highly localized, which may imply that the adsorption does not occur. If the adsorption forms an ionic bond, the $\mathrm{O}$ atom that connects to $\mathrm{Mg}$ is supposed to have a different degree of localization from other $\mathrm{O}$ atoms of $\mathrm{Cr}_{2} \mathrm{O}_{7}{ }^{2-}$ due to the different bonding atoms. In other words, $\mathrm{O}$ atoms only form bonds with $\mathrm{Mg}$ and $\mathrm{Si}$ atoms in octahedrons of montmorillonite- $\mathrm{Mg}$, thus identical localization of $\mathrm{O}$ atoms happens to prove formation of ionic bonds. In conclusion, all the isomorph forms a covalent bond after adsorption with the exception of montmorillonite- $\mathrm{Mg}$, which maintains its constructure via ionic bonds. 


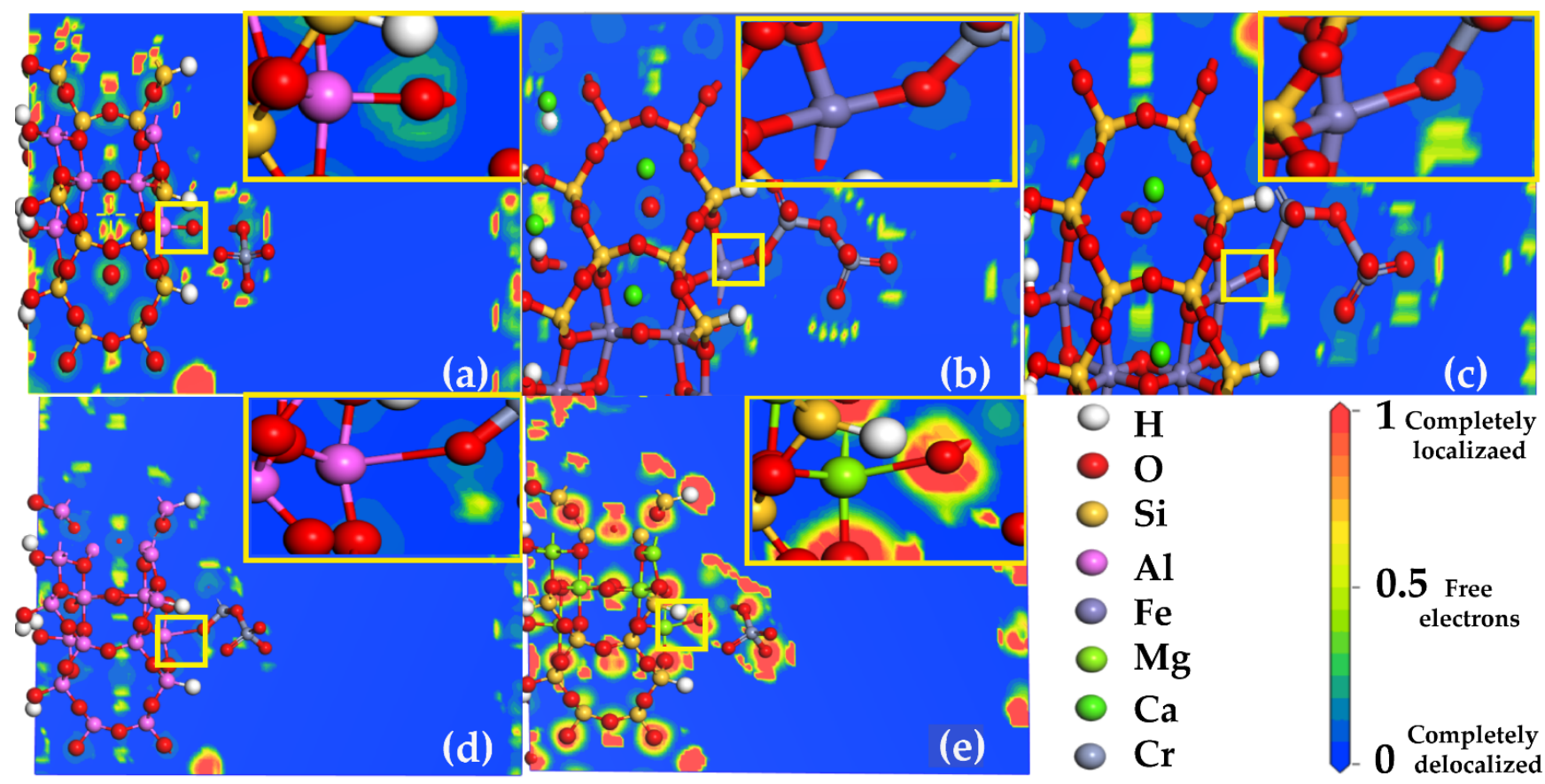

Figure 5. Electron localization function of (a) montmorillonite, (b) nontronite-Fe(II), (c) nontronite-Fe(III), (d) montmorillonite-Mg and (e) beidellite, and the white circle means the adsorption bond between mineral and $\mathrm{Cr}_{2} \mathrm{O}_{7}{ }^{2-}$.

\subsection{Density of States Reveal the Formation of Adsorption Bond}

The density of states demonstrates the distribution of valence electron orbitals and the valence electron energy of atoms (Figure 6). As shown in Figure 6a,b, the $p$-orbital of $\mathrm{O}$ atom splits into two orbitals at -2 and $+2 \mathrm{eV}$, and the $d$-orbital of $\mathrm{Cr}$ splits into three orbitals at $-15,-3$ and $3 \mathrm{eV}$. The degeneracy of $s-$ orbitals and $p$-orbitals of $\mathrm{Al}$ of montmorillonite after $\mathrm{Cr}(\mathrm{VI})$ adsorption was observed at 7.5 and $17 \mathrm{eV}$ (Figure 6). The splitting and left shift of electron orbitals indicates that the energy of the atom/molecule becomes lower, and the structure becomes more stable [61]. The energy overlaps of $p-$ orbital of $\mathrm{O}$ atom and $s$-orbitals, $p$-orbitals of $\mathrm{Al}$ verified that the adsorption is caused by formation of Al-O bond (Figure $6 \mathrm{c}, \mathrm{d}$ ). The disappearance of $d$-orbital electrons located at $3 \mathrm{eV}$ (Figure $6 \mathrm{~b}, \mathrm{e}$ ) implied that electrons have been transferred to the nearby $\mathrm{O}$ atom to form the adsorption bond. The overlaps of $d$-orbital of Fe and $p$-orbitals of $\mathrm{O}$ from -7.5 to $0 \mathrm{eV}$ confirmed that $\mathrm{Fe}$ has a strong $\mathrm{Cr}_{2} \mathrm{O}_{7}{ }^{2-}$ adsorption capacity including $\mathrm{Fe}(\mathrm{III})$, which is regarded as unable to reduce and adsorb $\mathrm{Cr}(\mathrm{VI})$ (Figure 6f, g,i,j). The $\mathrm{Cr}$ appears to play the same roles that gives its $d$-orbital electrons to nearby $\mathrm{O}$ atoms in all adsorption systems (Figure $6 \mathrm{~b}, \mathrm{e}, \mathrm{h}, \mathrm{k}, \mathrm{n}, \mathrm{q}$ ). Meanwhile, it is worth noting that the electrons in $p$-orbital of $\mathrm{Cr}$ are also transferred to the nearby $\mathrm{O}$ atom, since the height of PDOS (partial density of states) peak is reduced (Figure 6k), and such excessive electron transportation may have resulted from the electronegativity of Fe(III). Pecini et al. (2013) considered that the tetrahedral substitution leads negative charges within mineral layers [62], which has an effect on surface properties [63]. Hence, it is inferred that reduction of overlapping area of $s, p-$ orbitals of $\mathrm{Al}$ atoms caused by replacement of $\mathrm{Si}^{4+}$ by $\mathrm{Al}^{3+}$ in tetrahedrons. The DOS distribution of beidellite is similar to montmorillonite, and the degeneracy of s-orbitals and $\mathrm{p}$-orbitals at $-15,0 \mathrm{eV}$ is also caused by $\mathrm{Al}_{\mathrm{T}}$. The valence electrons of montmorillonite- $\mathrm{Mg}$ are only observed as $p$-orbital electrons located at $-40 \mathrm{eV}$ (Figure 61). It is implied that $\mathrm{Mg}$ is unable to form an adsorption bond with $\mathrm{Cr}_{2} \mathrm{O}_{7}{ }^{2-}$ owing to a lack of orbital energy overlaps (Figure $61, \mathrm{~m}$ ). Thus, the antibonding orbital valued -0.47 e does not exist, which is consistent with bond populations and Elf results. Given the high energy of valence electrons of $\mathrm{Mg}$, which is 2 to 20 times higher than the other four adsorption systems, it is reasonable to believe that the antibonding orbitals can build up octahedrons as ionic bonds. This is consistent with the $\mathrm{Mg}$ replacing the $\mathrm{Al}$ in natural clay minerals. 

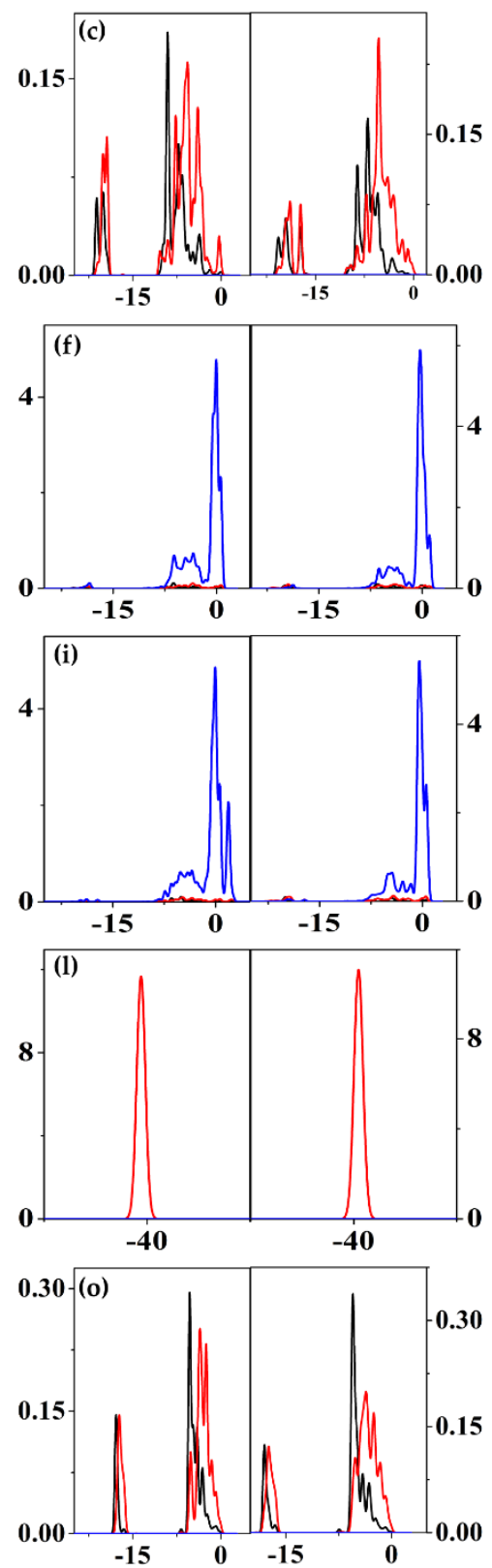
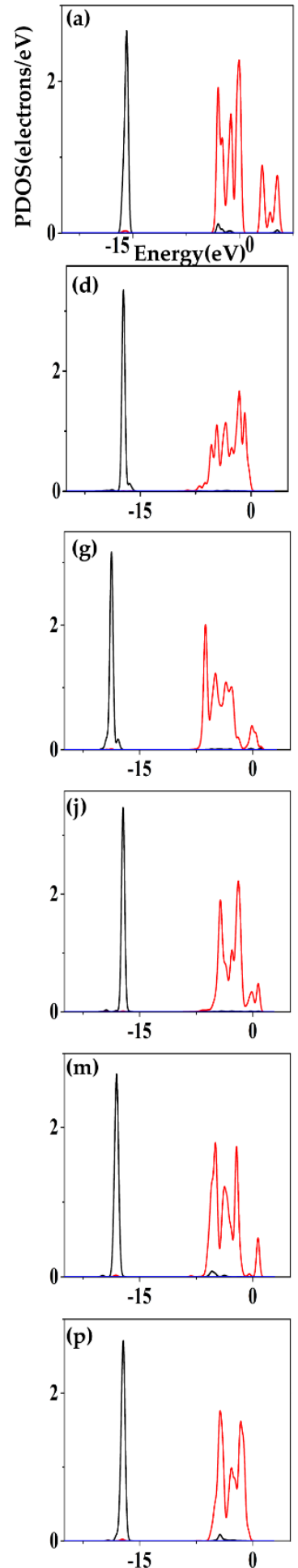
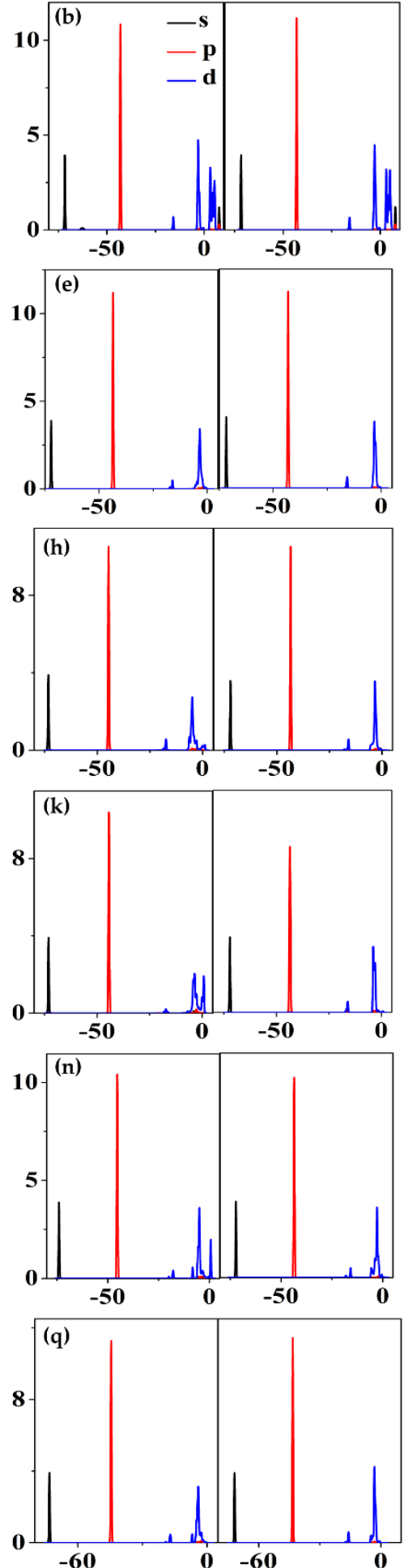

Figure 6. DOS of atoms of adsorption system. $(\mathbf{a}, \mathbf{d}, \mathbf{g}, \mathbf{j}, \mathbf{m}, \mathbf{p})$ : DOS of $\mathrm{O}$ atom of $\mathrm{Cr}_{2} \mathrm{O}_{7}^{2-} ;(\mathbf{b}, \mathbf{e}, \mathbf{h}, \mathbf{k}, \mathbf{n}, \mathbf{q})$ : DOS of $\mathrm{Cr}{ }_{-1}$ and $\mathrm{Cr}_{-2} ;(\mathbf{c}, \mathbf{f}, \mathbf{i}, \mathbf{l}, \mathbf{o})$ : DOS of montmorillonite, nontronite-(II), nontronite-(III), montmorillonite-Mg and beidellite, respectively.

\subsection{Band Structures Reveal the Strength of Adsorption Bond and the Distinctive Valence Electrons}

There are corresponding relationships between band structures and density of states. Every energy band represents the energy level of orbitals. Therefore, the width and intensity of the energy band in a specific energy range indicate the strength of chemical bonds. It is obvious that $\mathrm{Cr}(\mathrm{VI})$ adsorption introduces its orbital electrons into the electron 
hybrid orbitals of clay minerals at -5 to 0 energy range (Figure $7 \mathrm{a}, \mathrm{c}, \mathrm{e}, \mathrm{i}$ ). Hence, based on the bond populations and Elf results, it is discovered that the covalent bond formed by spd hybridization from density of states (Figure 7a,c,e,g). Correspondingly, the band structure of every adsorption system showed denser (Figure 7b,j) or wider (Figure 7d,f) energy bands.
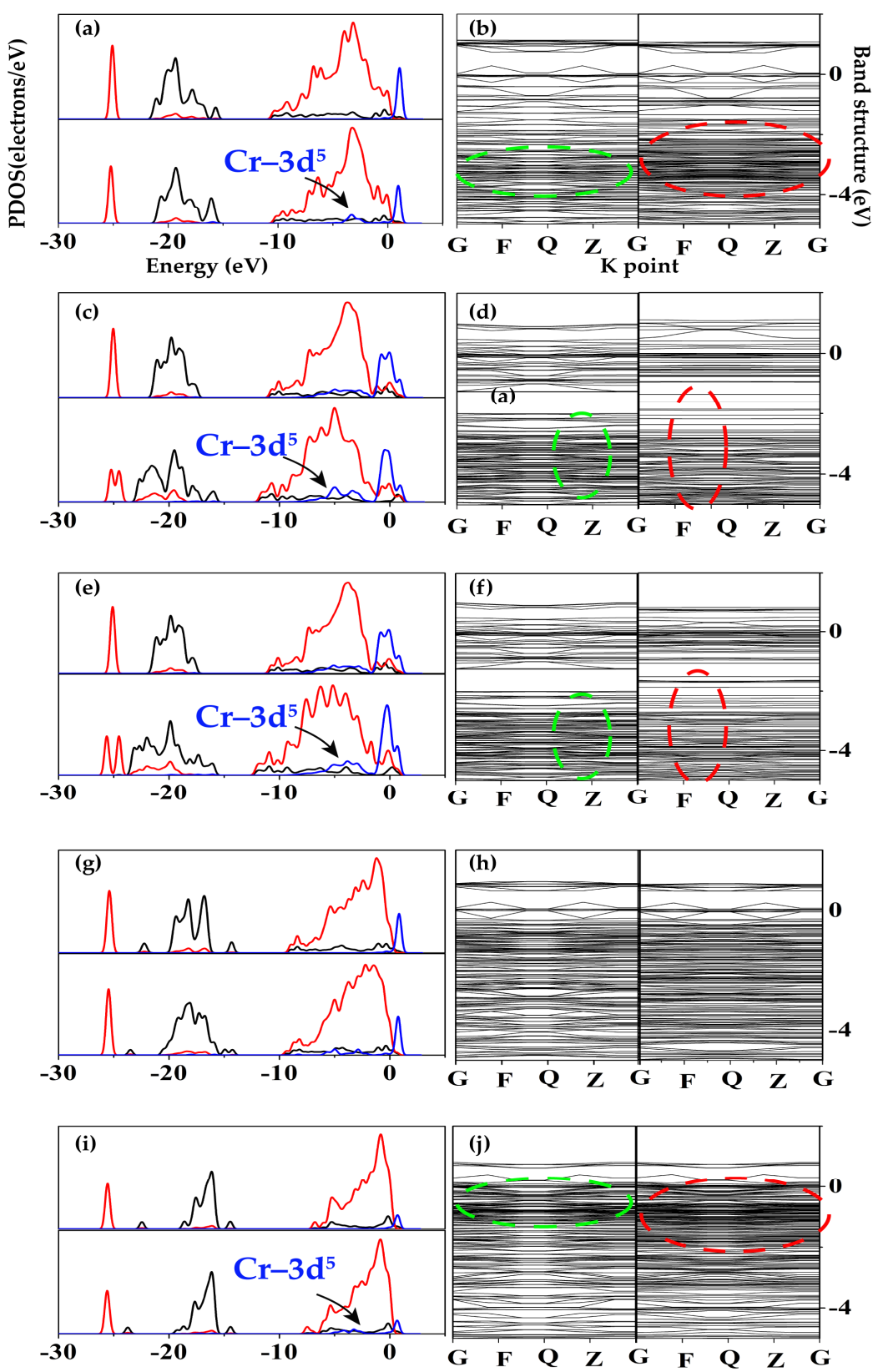

Figure 7. DOS and band structure of adsorption system. (a):DOS of montmorillonite; (b): band structure of montmorillonite; (c): DOS of nontronite-Fe(II); (d): band structure of nontronite-(II); (e): DOS of nontronite-Fe(III); (f): band structure of nontronite-(III); (g): DOS of montmorillonite-Mg; (h): band structure of montmorillonite-Mg; (i): DOS of beidellite; (j): band structure of beidellite.

However, the $d$-orbital electrons of $\mathrm{Cr}$ were not found in the montmorillonite- $\mathrm{Mg}$ adsorption system (Figure $7 \mathrm{~g}$ ). The band structure showed no obvious variation between pure montmorillonite-Mg and the adsorption system (Figure $7 \mathrm{~h}$ ). From the results of bond populations, Elf, and density of states and band structures of montmorillonite- $\mathrm{Mg}$, it can be inferred that the bare octahedral edge $\mathrm{Mg}$ has no interaction with $\mathrm{Cr}_{2} \mathrm{O}_{7}{ }^{2-}$. Much of the previous research in chromium-adsorbed synthetic materials has proved that magnesium 
composite has a promising application in the field of adsorption of heavy metals, such as chromium and lead [64-69]. Given the peripheral electron configuration of $\mathrm{Mg}\left([\mathrm{Ne}] 3 \mathrm{~s}^{2}\right)$, the crystal field generated by the $\mathrm{T}-\mathrm{O}-\mathrm{T}$ (tetrahedron-octahedron-tetrahedron) structure results in the uniform transportation of the s-orbitals valence electrons to neighboring atoms. Therefore, the observed valence electrons were $p$-orbital electrons. In other words, in such synthetic materials, $\mathrm{Mg}$ probably maintains its $3 s$-orbitals as the active valence electrons participating in the adsorption. In other words, different crystal/coordination fields give rise to different frontier orbitals, such as the DOS of magnesium in chlorophyll [70]. Without the influence of coordination fields, $\mathrm{Mg}$ has the ideal valence electron state for adsorption of hexavalent chromium [71]. From another point of view, even if the valence electrons of magnesium are disturbed by the coordination fields, its high-energy $p$-orbitals electrons (about $8 \mathrm{eV}$ ) are sufficient to enter the antibonding orbitals, forming an ionic bond to maintain bond stability.

\section{Conclusions}

This paper investigated the adsorption mechanism of montmorillonite, nontronite, beidellite by means of density function theory. Therein, the structural Fe(II/III) of nontronite and the structural $\mathrm{Mg}$ of montmorillonite were discussed separately. The ICP-OES and SEM-EDS results indicated the adsorption capacity of $\mathrm{Cr}(\mathrm{VI})$ as follows: montmorillonite $(12 \mathrm{mg} / \mathrm{g})>$ nontronite $(9 \mathrm{mg} / \mathrm{g})>$ beidellite $(8 \mathrm{mg} / \mathrm{g})$. The calculation results supplement and illustrate the experimental results, especially for the role of structural magnesium of montmorillonite. The Mulliken populations considered montmorillonite and nontronite to be in the same category, with key populations of $0.48 \sim 0.52 \mathrm{e}$, and beidellite to be in another category with key populations of $0.12 \mathrm{e}$, and explained why beidellite has the lowest hexavalent chromium uptake. Moreover, the adsorption bonds of all adsorption systems except the Mg doped system were covalent bonds due to the bond populations. The electron localization function further confirmed that the adsorption bonds are covalent bonds, except the $\mathrm{Mg}$ doped isomorph. The density of states demonstrated the formation of adsorption bonds via the overlapping $p$-orbitals of $\mathrm{O}$ and $s / p / d$-orbitals of different substitutional atoms $(-5 \sim 0 \mathrm{eV})$. The band structures testified that the overlapping orbitals led to wider and denser energy bands, which indicates the formation of a strong adsorption bond. However, while $\mathrm{Mg}$ replaces the $\mathrm{Al}$ in octahedrons, the antibonding orbitals were observed inside the octahedrons and at the adsorption sites by Mulliken populations. Electron localization function showed that an ionic bond may form in octahedrons, and that no bond is formed between mineral and $\mathrm{Cr}_{2} \mathrm{O}_{7}{ }^{2-}$. Based on the density of states and band structures, antibonding orbitals supporting the octahedrons were occupied by $p$-orbital electrons of $\mathrm{Mg}$ due to the high electron energy of approximately $8 \mathrm{eV}$. Since there were no overlapping orbitals and the unchanged energy bands, the structural $\mathrm{Mg}$ would not adsorb the $\mathrm{Cr}_{2} \mathrm{O}_{7}{ }^{2-}$.

This work provides new perspectives to understand the effect of lattice substitution of clay minerals on hexavalent chromium adsorption, and is beneficial for modified clay mineral materials applications.

Author Contributions: All authors contributed to this manuscript. W.L. conceived and designed the study. W.L. performed the experiments. W.L. completed the calculation. W.L. performed the data analysis and wrote this manuscript. Z.Z. and B.L. completed the supervision. Z.Z. and B.L. provided the research funding. All authors have read and agreed to the published version of the manuscript.

Funding: The authors acknowledge the financial supports by the National Natural Science Foundation of China (41872039 and 41831285).

Data Availability Statement: The data presented in this study are available on request from the corresponding author.

Acknowledgments: Thanks to X.-R.L. and X.-Y.S. for personal research funding support.

Conflicts of Interest: The authors declare no conflict of interest. 


\section{References}

1. Wilbur, S.; Abadin, H.; Fay, M.; Yu, D.; Tencza, B.; Ingerman, L.; Klotzbach, J.; Jmaes, S. Toxicological Profile for Chromium; Agency for Toxic Substances and Disease Registry (US): Atlanta, GA, USA, 2012.

2. Zeng, Z.; Luo, W.; Wang, Z.; Yi, F. Water Pollution and Its Causes in the Tuojiang River Basin, China: An Artificial Neural Network Analysis. Sustainability 2021, 13, 792. [CrossRef]

3. Zeng, Z.; Luo, W.; Yi, F.; Huang, F.; Wang, C.; Zhang, Y.; Cheng, Q.; Wang, Z. Horizontal Distribution of Cadmium in Urban Constructed Wetlands: A Case Study. Sustainability 2021, 13, 5381. [CrossRef]

4. Dai, R.; Liu, J.; Yu, C.; Sun, R.; Lan, Y.; Mao, J. A comparative study of oxidation of Cr(1ll) in aqueous ions, complex ions and insoluble compounds by manganese-bearing mineral(birnessite). Chemosphere 2009, 76, 536-541. [CrossRef]

5. Aldrich, M.; Gardea-Torresdey, J.; Peralta-Videa, J.; Parsons, J. Uptake and reduction of Cr(VI) to Cr(III) by mesquite (Prosopis spp.): Chromate-plant interaction in hydroponics andsolid media studied using XAS. Environ. Sci. Technol. 2003, 37, 1859-1864. [CrossRef] [PubMed]

6. DesMarias, T.; Costa, M. Mechanisms of chromium-induced toxicity. Curr. Opin. Toxicol. 2019, 14, 1-7. [CrossRef]

7. Kaya, A.; Ören, A. Adsorption of zinc from aqueous solutions to bentonite. J. Hazard. Mater. 2005, 125, 183-189. [CrossRef] [PubMed]

8. Andini, S.; Cioffi, R.; Montagnaro, F.; Pisciotta, F.; Santoro, L. Simultaneous adsorption of chlorophenol and heavy metal ions on organophilic bentonite. Appl. Clay Sci. 2006, 31, 126-133. [CrossRef]

9. Donat, R.; Akdogan, A.; Erdem, E.; Cetisli, H. Thermodynamics of $\mathrm{Pb}^{2+}$ and $\mathrm{Ni}^{2+}$ adsorption onto natural bentonite from aqueous solutions. J. Colloid Interface Sci. 2005, 286, 43-52. [CrossRef]

10. Anna, B.; Kleopas, M.; Constantine, S.; Anestis, F.; Maria, B. Adsorption of Cd(II), Cu(II), Ni(II) and Pb(II) onto natural bentonite: Study in mono- and multi-metal systems. Environ. Earth Sci. 2015, 73, 5435-5444. [CrossRef]

11. Tohdee, K.; Kaewsichan, L.; Asadullah. Enhancement of adsorption efficiency of heavy metal Cu(II) and Zn(II) onto cationic surfactant modified bentonite. J. Environ. Chem. Eng. 2018, 6, 2821-2828. [CrossRef]

12. Liu, Z.; Zhou, S. Adsorption of copper and nickel on Na-bentonite. Process. Saf. Environ. Prot. 2010, 88, 62-66. [CrossRef]

13. Rathnayake, S.; Martens, W.; Xi, Y.; Frost, R.; Ayoko, G. Remediation of Cr (VI) by inorganic-organic clay. J. Colloid Interface Sci. 2017, 490, 163-173. [CrossRef]

14. Hu, B.; Luo, H. Adsorption of hexavalent chromium onto montmorillonite modified with hydroxyaluminum and cetyltrimethylammonium bromide. Appl. Surf. Sci. 2010, 257, 769-775. [CrossRef]

15. Castro-Castro, J.; Macías-Quiroga, I.; Giraldo-Gómez, G.; Sanabria-González, N. Adsorption of Cr(VI) in Aqueous Solution Using a Surfactant-Modified Bentonite. Sci. World J. 2020, 2020, 3628163. [CrossRef]

16. Abollino, O.; Acetob, M.; Malandrinoa, M.; Sarzaninia, C.; Mentastia, E. Adsorption of heavy metals on Na-montmorillonite. Effect of $\mathrm{pH}$ and organic substances. Water Res. 2003, 37, 1619-1627. [CrossRef]

17. Singh, R.; Dong, H.; Zeng, Q.; Zhang, L.; Rengasamy, K. Hexavalent chromium removal by chitosan modified-bioreduced nontronite. Geochim. Cosmochim. Acta 2017, 210, 25-41. [CrossRef]

18. Kwak, S.; Yoo, J.; Baek, K. Synergistic and inhibitory reduction of $\mathrm{Cr}$ (VI) by montmorillonite, citric acid, and Mn(II). J. Soils Sediments 2018, 18, 205-210. [CrossRef]

19. Öncel, M. Adsorption of copper (II) from aqueous solution by Beidellite. Environ. Geol. 2008, 55, 1767-1775. [CrossRef]

20. Bhattacharyya, K.; Gupta, S. Adsorption of a few heavy metals on natural and modified kaolinite and montmorillonite: A review. Adv. Colloid Interface Sci. 2008, 140, 114-131. [CrossRef]

21. Shu, Z.; Liu, L.; Qiu, G.; Yang, X.; Zhang, M.; Tan, W.; Liu, C.; Wu, F. Photochemical formation process of schwertmannite on montmorillonite and corresponding Cr (VI) adsorption capacity. ACS Earth Space Chem. 2019, 3, 718-727. [CrossRef]

22. Handy, N.C.; Lee, A. The adiabatic approximation. Chem. Phys. Lett. 1996, 252, 425-430. [CrossRef]

23. Echenique, P.; Alonso, J.L. A mathematical and computational review of Hartree-Fock SCF methods in Quantum Chemistry. Mol. Phys. 2007, 105, 3057-3098. [CrossRef]

24. Kolmanovich, V.; Reznik, I. Decompositions of electron density and the shell problem in Hohenberg-Kohn functional theory. Solid State Commun. 1984, 50, 117-120. [CrossRef]

25. Nagy, Á. Kohn-Sham equations for multiplets. Phys. Rev. A 1998, 57, 1672-1677. [CrossRef]

26. Cottenier, S. Density Functional Theory and the Family of $(L)$ APW-Methods: A Step-by-Step Introduction; Instituut Voor Kernen Stralingsfysica: Leuven, Belgium, 2002.

27. Jackson, K.; Pederson, M.R. Accurate forces in a local-orbital approach to the local-density approximation. Phys. Rev. B 1990, 42, 3276-3281. [CrossRef] [PubMed]

28. Perdew, J.P.; Yue, W. Erratum: Accurate and simple density functional for the electronic exchange energy: Generalized gradient approximation. Phys. Rev. B 1989, 40, 3399. [CrossRef]

29. Kohn, W. Electronic structure of matter-wave functions and density funcionals. Riv. Morden Phys. 1999, 71, 1253-1266.

30. Ceperley, D.; Berni, J. Ground state of the electron gas by a stochastic method. Phys. Rev. Lett. 1980, 45, 566-569. [CrossRef]

31. Perdew, J.; Yue, W. Accurate and simple density functional for the electronic exchange energy: Generalized gradient approximation. Phys. Rev. B 1986, 33, 8800-8802. [CrossRef]

32. Kirkpatrick, S.; Gelatt, C.; Vecchi, M. Optimization by simulated annealing. Science 1983, 220, 671-680. [CrossRef] [PubMed] 
33. Clark, S.; Segall, M.; Pickard, C.; Hasnip, P.; Probert, M.; Refson, K.; Payne, M. First principles methods using CASTEP. Z. Krist.-Cryst. Mater. 2005, 220, 567-570. [CrossRef]

34. Delley, B. DMol3 DFT studies: From molecules and molecular environments to surfaces and solids. Comput. Mater. Sci. 2000, 17, 122-126. [CrossRef]

35. Rani, P.; Dubey, G.; Jindal, V. DFT study of optical properties of pure and doped graphene. Phys. E Low-Dimens. Syst. Nanostruct. 2014, 62, 28-35. [CrossRef]

36. Ossiander, M.; Riemensberger, J.; Neppl, S.; Mittermair, M.; Schaffer, M.; Duensing, A.; Wagner, M.; Heider, R.; Wurzer, M.; Gerl, M.; et al. Absolute timing of the photoelectric effect. Nature 2018, 561, 374-377. [CrossRef]

37. Madejová, J. FTIR techniques in clay mineral studies. Vib. Spectrosc. 2003, 31, 1-10. [CrossRef]

38. Soleimani, M.; Siahpoosh, Z. Ghezeljeh nanoclay as a new natural adsorbent for the removal of copper and mercury ions: Equilibrium, kinetics and thermodynamics studies. Chin. J. Chem. Eng. 2015, 23, 1819-1833. [CrossRef]

39. Viani, A.; Gualtieri, A.; Artioli, G. The nature of disorder in montmorillonite by simulation of X-ray powder patterns. Am. Mineral. 2002, 87, 966-975. [CrossRef]

40. Manceau, A.; Chateigner, D.; Gates, W. Polarized EXAFS, distance-valence least-squares modeling (DVLS), and quantitative texture analysis approaches to the structural refinement of Garfield nontronite. Phys. Chem. Miner. 1998, 25, 347-365. [CrossRef]

41. Li, H.; Bian, L.; Dong, F.; Li, W.; Song, M.; Nie, J.; Liu, X.; Huo, T.; Zhang, H.; Xu, B.; et al. DFT and 2D-CA methods unravelling the mechanism of interfacial interaction between amino acids and Ca-montmorillonite. Appl. Clay Sci. 2019, 183, 105356. [CrossRef]

42. Bian, L.; Dong, F.; Song, M.X.; Dong, H.; Li, W.; Duan, T.; Xu, J.; Zhang, X. DFT and two-dimensional correlation analysis methods for evaluating the $\mathrm{Pu}^{3+}-\mathrm{Pu}^{4+}$ electronic transition of plutonium-doped zircon. J. Hazard. Mater. 2015, 294, 47-56. [CrossRef]

43. Bian, L.; Song, M.; Dong, F.; Duan, T.; Xu, J.; Li, W.; Zhang, X. DFT and two-dimensional correlation analysis for evaluating the oxygen defect mechanism of low-density $4 \mathrm{f}$ (or 5f) elements interacting with Ca-Mt. RSC Adv. 2015, 5, 28601-28610. [CrossRef]

44. Bian, L.; Xu, J.; Song, M.; Dong, F.; Dong, H.; Shi, F.; Zhang, X.; Duan, T. First principles simulation of temperature dependent electronic transition of FM-AFM phase BFO. J. Mol. Modeling 2015, 21, 91. [CrossRef] [PubMed]

45. Perdew, J.; Burke, K.; Ernzerhof, M. Generalized gradient approximation made simple. Phys. Rev. Lett. 1996, 77, 3865. [CrossRef]

46. Tkatchenko, A.; Scheffler, M. Accurate Molecular Van Der Waals Interactions from Ground-State Electron Density and Free-Atom Reference Data. Phys. Rev. Lett. 2009, 102, 073005. [CrossRef] [PubMed]

47. He, L.; Zhang, Y.; Zang, Y.Z.; Liu, C.; Wang, W.; Han, R.; Ji, N.; Zhang, S.; Liu, Q. Promotion of A-Site Ag-Doped Perovskites for the Catalytic Oxidation of Soot: Synergistic Catalytic Effect of Dual Active Sites. ACS Catal. 2021, 11, 14224-14236. [CrossRef]

48. Liu, X.; Yang, S.; Gu, P.; Liu, S.; Yang, G. Adsorption and removal of metal ions by smectites nanoparticles: Mechanistic aspects, and impacts of charge location and edge structure. Appl. Clay Sci. 2021, 201, 105957. [CrossRef]

49. Garfinkel-Shweky, D.; Yariv, S. Metachromasy in clay dye systems: The adsorption of acridine orange by Na-beidellite. Clay Miner. 1999, 34, 459-467. [CrossRef]

50. Greathouse, J.; Cygan, R. Water structure and aqueous uranyl (VI) adsorption equilibria onto external surfaces of beidellite, montmorillonite, and pyrophyllite: Results from molecular simulations. Environ. Sci. Technol. 2006, 40, 3865-3871. [CrossRef] [PubMed]

51. Peng, C.; Min, F.; Liu, L.; Chen, J. The adsorption of $\mathrm{CaOH}^{+}$on (001) basal and (010) edge surface of Na-montmorillonite: A DFT study. Surf. Interface Anal. 2007, 49, 267-277. [CrossRef]

52. Chen, J.; Min, F.; Liu, L.; Liu, C. Mechanism research on surface hydration of kaolinite, insights from DFT and MD simulations. Appl. Surf. Sci. 2019, 476, 6-15. [CrossRef]

53. Cygan, R.; Liang, J.; Kalinichev, G. Molecular models of hydroxide, oxyhydroxide, and clay phases and the development of a general force field. J. Phys. Chem. B 2004, 108, 1255-1266. [CrossRef]

54. Segall, M.; Shah, R.; Pickard, C.; Payne, M. Population analysis of plane-wave electronic structure calculations. Phys. Rev. B 1996, 54, 16317-16320. [CrossRef]

55. Segall, M.; Pickard, C.; Shah, R.; Payne, M. Population analysis in plane wave electronic structure calculations. Mol. Phys. 2010, 89, 571-577. [CrossRef]

56. Peng, C.; Zhong, Y.; Wang, G.; Min, F.; Qin, L. Atomic-level insights into the adsorption of rare earth $\mathrm{Y}(\mathrm{OH}) 3-\mathrm{nn}+(\mathrm{n}=1-3)$ ions on kaolinite surface. Appl. Surf. Sci. 2019, 469, 357-367. [CrossRef]

57. Zhang, Z.; Zhou, Q.; Zhuang, L.; Zhao, Z. Adsorption of $\mathrm{Ca}(\mathrm{II})$ and $\mathrm{K}(\mathrm{I})$ on the kaolinite surface: A DFT study with an experimental verification. Mol. Phys. 2020, 119, 9. [CrossRef]

58. Levitt, M.; Raleigh, D.; Creuzet, F.; Griffin, R. Theory and simulations of homonuclear spin pair systems in rotating solids. J. Chem. Phys. 1990, 92, 6347-6364. [CrossRef]

59. Miroslav, K.; Wagner, F.; Grin, Y. Electron localization function for transition-metal compounds. Theor. Chem. Acc. 2002, 108, 150-156. [CrossRef]

60. Sproul, G. Electronegativity and bond type: Predicting bond type. J. Chem. Educ. 2001, 78, 387. [CrossRef]

61. Thomas, U.; Erastova, V.; Greenwell, H. Ion adsorption at clay-mineral surfaces: The Hofmeister series for hydrated smectite minerals. Clays Clay Miner. 2016, 64, 472-487. [CrossRef]

62. Pecini, E.; Marcelo, J. Measuring the isoelectric point of the edges of clay mineral particles: The case of montmorillonite. Langmuir 2013, 29, 14926-14934. [CrossRef] 
63. Gu, S.; Kang, X.; Wang, L.; Lichtfouse, E.; Wang, C. Clay mineral adsorbents for heavy metal removal from wastewater: A review. Environ. Chem. Lett. 2019, 17, 629-654. [CrossRef]

64. Li, Y.; Gao, B.; Wu, T.; Sun, D.; Li, X.; Wang, B.; Lu, F. Hexavalent chromium removal from aqueous solution by adsorption on aluminum magnesium mixed hydroxide. Water Res. 2009, 43, 3067-3075. [CrossRef]

65. Bharti, V.; Balomajumder, C. Magnetic magnesium ferrite-doped multi-walled carbon nanotubes: An advanced treatment of chromium-containing wastewater. Environ. Sci. Pollut. Res. 2020, 27, 13844-13854. [CrossRef]

66. Ebrahim, S.; Ahmed, M.; Saad, E.; Salem, S.; Ahmed, A.; Mahmoud, H.; Fayez, M.; Hosam, A.; Essa, M.; Amr, F. The Catalytic Activity of Biosynthesized Magnesium Oxide Nanoparticles (MgO-NPs) for Inhibiting the Growth of Pathogenic Microbes, Tanning Effluent Treatment, and Chromium Ion Removal. Catalysts 2021, 11, 821. [CrossRef]

67. Matsukevich, I.; Lipai, Y.; Romanovski, V. Cu/MgO and Ni/MgO composite nanoparticles for fast, high-efficiency adsorption of aqueous lead (II) and chromium (III) ions. J. Mater. Sci. 2021, 56, 5031-5040. [CrossRef]

68. Alshammari, M.; Ahmed, I.; Alsharari, J.; Alsohaimi, I.; Al-Muaikel, N.; Alraddadi, T.; Hasanin, T. Adsorption of Cr (VI) using $\alpha-\mathrm{Fe}_{2} \mathrm{O}_{3}$ coated hydroxy magnesium silicate (HMS): Isotherm, thermodynamic and kinetic study. Int. J. Environ. Anal. Chem. 2021, 1-17. [CrossRef]

69. Abdollah, D.; Hafez, G.; Parviz, D.; Amir, K.; Sye, H.; Ali, P.; Alireza, B. An investigation and comparison of removing heavy metals (lead and chromium) from aqueous solutions using magnesium oxide nanoparticles. Pol. J. Environ. Stud. 2016, 25, 557-562.

70. Zeng, Z.; Luo, W.; Yi, F.; Wang, Z. Cadmium Uptake, In Vivo Metastasis and Subcellular Environmental Response of Five Wetland Plants Using DFT Method. Sustainability 2021, 13, 7872. [CrossRef]

71. Alessio, S.; Curcio, G.; Limonti, C. Hexavalent chromium reduction by zero-valent magnesium particles in column systems. J. Environ. Manag. 2021, 293, 112905. [CrossRef] 